\title{
El origen de los indios, la reconquista de Jerusalén y el fin de los tiempos en la Historia de los indios de la Nueva España, de fray Toribio de Benavente, «Motolinía»

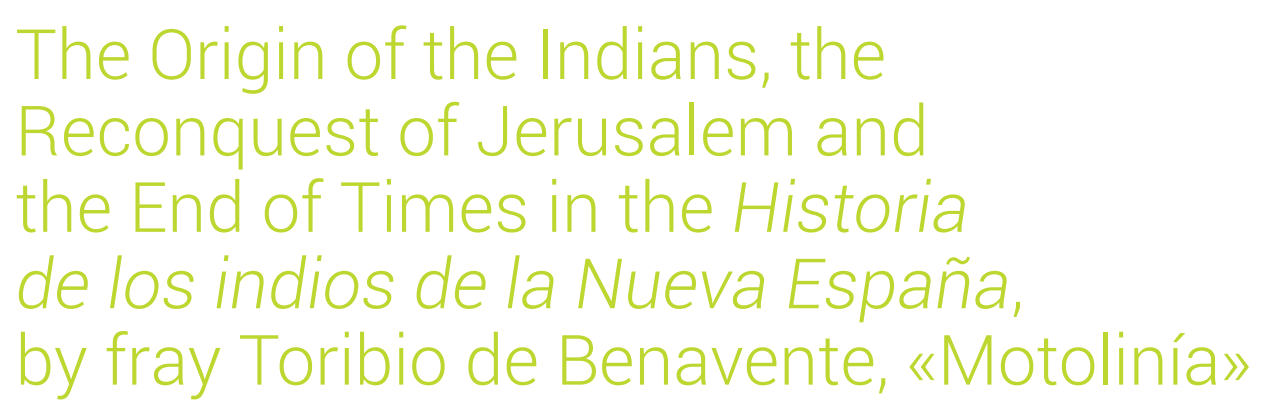

\section{Mercedes Serna}

Universidad de Barcelona

ESPAÑA

serna@ub.edu

[Hipogrifo, (issn: 2328-1308), 8.1, 2020, pp. 295-306]

Recibido: 09-09-2019 / Aceptado: 01-10-2019

DOI: http://dx.doi.org/10.13035/H.2020.08.01.21

Resumen. En el presente artículo, estudiamos, a través de la obra Historia de los indios de la Nueva España y de los Memoriales, la propagación o defensa que realiza fray Toribio de Benavente, «Motolinía», de ciertas ideas o creencias como el milenarismo (con la pretensión de sentar las bases para la instauración del reino milenario), la reconquista de Jerusalén o el apoyo al sacramento del bautismo, tal como era administrado por los franciscanos.

Palabras clave. Conquista; Jerusalén; milenarismo; origen; indios; fin del mundo.

Abstract. The present article focuses on the Historia de los indios de la Nueva España and Memoriales, by fray Toribio de Benavente, «Motolinía». The aim is 
to study the author's propagation, or defence, of certain ideas or beliefs such as millenarianism (with the intention of preparing the establishment of the millennial kingdom), the recovery of Jerusalem, and support for the sacrament of baptism as it was administered by the Franciscans.

Keywords. Conquest; Jerusalem; Millenarianism; Origin; Indians; End of the world.

\section{MOTOLINÍA Y TLAXCALA}

Fray Toribio de Benavente o de Paredes, viajero infatigable, apóstol del milenarismo, polemista acérrimo, misionero e investigador de los ritos y costumbres de los mexicas, llegó, junto con un grupo inicial de franciscanos, a México, en 1524, con la finalidad de evangelizar y proteger a los indios. Este zamorano tomaría los hábitos religiosos sobre 1516 y un año después se trasladaría a la custodia de San Gabriel, de Extremadura, posiblemente por mandato de fray Martín de Valencia. Según Baudot?, es en dicha custodia donde se iniciarán los vínculos de Motolinía con la reforma espiritual seráfica que trasladará a su obra historiográfica y se encarnará en su vocación misionera. Tal como he señalado en otras ocasiones², la orden seráfica se propuso una interpretación más estricta de la regla franciscana, sobre todo del voto de pobreza, y, además, tenía un fuerte espíritu milenario. Entre 1517 y 1523 se consolida el ideario de Motolinía basado en el culto a la pobreza y el rechazo a la iglesia oficial, y con una visión del Nuevo Mundo como una tierra prometida donde desarrollar un cristianismo primitivo y auténtico ${ }^{3}$. Es decir que nuestro autor, antes de partir el 25 de enero de 1524, desde el puerto de Sanlúcar de Barrameda ${ }^{4}$, acompañado del cabeza de la expedición, fray Martín de Valencia y sus otros compañeros hacia las nuevas tierras, ya tenía la intención de llevar a cabo estas ideas de reforma. La famosa misión de los 12 llegó a Ciudad de México el 18 de junio de 1524, tras haber recorrido a pie, como lo exigía el voto de pobreza franciscano, 400 kilómetros, desde San Juan de Ulúa. Motolinía y sus compañeros de orden fueron recibidos por el propio Hernán Cortés y sus capitanes y caballeros, así como por los caciques y nobles aztecas, con gran acatamiento.

En 1536, Motolinía fue nombrado, durante la celebración del primer capítulo provincial del Santo Evangelio, guardián del monasterio de Tlaxcala, cargo que desempeñará hasta 1542. Durante todos estos años, se dedicó a recoger información de primera mano sobre los ritos, costumbres y festividades de los indios. Toda

\footnotetext{
1. Baudot, 1983, p. 18.

2. Serna, 2014, p. 11. Algunos de estos pasajes los he reelaborado a partir de mi edición de la Historia de los indios de la Nueva España, de 2014.

3. Baudot, 1983, p. 251.

4. Motolinía nos da una información exhaustiva de su viaje hacia el Nuevo Mundo en el capítulo tercero, de la «Segunda parte» de su Historia. Todas las referencias a la Historia de los indios de la Nueva España, de Motolinía, están extraídas de la citada edición de 2014.
} 
esta información aparecerá en sus Memoriales ${ }^{5}$ y en el capítulo 15 de la «Primera parte» de la Historia de los indios de la Nueva España. En dicho capítulo, nuestro autor describirá las fiestas del Corpus Christi y de San Juan de Tlaxcala celebradas en 1538. En este sentido, los Memoriales son un material importantísimo para conocer las andanzas de nuestro fraile y las festividades y celebraciones realizadas en estos años, algunas junto a los indios, como la vivida en 1540 por la Pascua de Resurrección, en el monasterio del pueblo de Tehuacán, donde se nos dice «que llegaban indios principales, de hasta más de cuarenta provincias de los alrededores, a celebrar la Semana Santa» ${ }^{6}$. Es en 1536 cuando, como indica nuestro autor en el «Preámbulo» de la «Segunda parte» de su Historia”, se le encomendó la tarea de realizar una profunda investigación sobre los ritos y costumbres de los mexicas, desde el punto de vista histórico y etnográfico. Esa investigación dio como fruto la Historia de los indios de la Nueva España y la obra histórica perdida, denominada por O'Gorman ${ }^{8}$, Libro perdido, de la que la primera podría ser un resumen. Esta investigación seguía o era continuación de la iniciada en $1533^{9}$, por fray Andrés de Olmos. Con ella pretendía realizar un primer balance historiográfico de la «conquista espiritual» así como, según los críticos partidarios de la tesis milenarista, sentar las bases para la instauración del reino milenario.

En conclusión, Motolinía comenzó a escribir la Historia de los indios de la Nueva España en 1536. Durante todos estos años, se dedicó, siendo guardián del convento de Tlaxcala, tanto a la evangelización y predicación como a la recopilación de la mayor información posible para la realización de su gran obra.

Los años que fray Toribio vivió en Tlaxcala destacan también por el auge de las representaciones teatrales de carácter evangelizador o catequístico, como señala Guadalupe Alemán ${ }^{10}$.

Fray Toribio también asesoró, desde su vida en Tlaxcala, a los frailes recién llegados a la Nueva España y tomó parte en las diferentes disputas habidas entre las órdenes religiosas, particularmente en aquéllas originadas por las críticas de los dominicos y agustinos contra la práctica franciscana de los bautizos masivos. Los cronistas, en general, presentan a fray Toribio como uno de los bautistas más activos, al afirmar que, en aquella época, de los más de seis millones de indios que

5. Motolinía, Memoriales, I, XXVII, pp. 40-41.

6. Motolinía, Memoriales, I, XXXVII, p. 54.

7. Así consta en el «Preámbulo» de la «Segunda parte»: «Estando yo descuidado y sin ningún pensamiento de escrebir semejante cosa que ésta, la obidiencia me mandó que escribiese algunas cosas notables de estos naturales, de las que en esta tierra la bondad divina ha encomenzado a obrar, y siempre obra; y también para que los que adelante vinieren, sepan y entiendan cuán notables cosas acontecieron en esta Nueva España, y los trabajos e infortunios que por los grandes pecados que en ella se cometían Nuestro Señor permitió que pasase, y la fe y religión que en ella el día de hoy se conserva, y aumentará adelante, siendo Nuestro Señor de ello servido» (Motolinía, Historia de los indios de la Nueva España, p. 183). 8. O'Gorman, 1989.

9. Una copia manuscrita se encuentra en la Biblioteca Nacional de España (Madrid), signatura Res. 165.3, fols. 20-102.

10. Alemán, 2013, p. 18. 
habría bautizado la orden seráfica, solo él «bautizó por cuenta que tuvo en escrito más de cuatrocientos mil, sin los que se le podrían olvidar» ${ }^{11}$.

Como ya ha señalado en distintas ocasiones Francisco Morales, los franciscanos, siguiendo el ejemplo iniciado en las Antillas y Cumaná, tuvieron un papel capital en la Nueva España, por muchos y distintos motivos. En primer lugar, fueron los verdaderos iniciadores de la evangelización; asimismo, fueron, de entre todas las órdenes, los primeros en llegar a la Nueva España'2; además, muchos de ellos tenían una excelente preparación intelectual y sobre todo educativa, como es el caso de los tres flamencos, Pedro de Gante, fray Juan de Tecto y fray Juan de Agora; iban con un plan muy definido y, según Morales ${ }^{13}$, bajo la protección de las altas autoridades eclesiásticas; por último, las reglas del franciscanismo observante, sobre todo el voto de pobreza y humildad, así como un cierto antiintelectualismo y una especial conexión con la naturaleza, influyeron en el acercamiento que los frailes franciscanos tuvieron con el indígena y, como consecuencia, en las grandes muestras de cariño y confianza del pueblo mexica hacia ellos, como se refleja en la Historia, de Motolinía.

Los franciscanos comprendieron, defendieron y rescataron el legado cultural de los indígenas, comportándose como verdaderos humanistas.

\section{MOTOLINÍA Y LA REFORMA SERÁFICA}

La reforma de la orden seráfica, iniciada en 1496 por fray Juan de Guadalupe, fue llevada a México por los primeros misioneros franciscanos, con fray Martín de Valencia a la cabeza. Dicha reforma, como señala Baudot, «se presentaba como una interpretación más estricta de la regla franciscana, insistiendo en mayor austeridad y en mayor anhelo de pobreza evangélica» pero, sobre todo, «pretendía una renovación espiritual de muy altos vuelos reanudando con las esperanzas milenarias y las lecturas apocalípticas del fraile calabrés, Joaquín de Fiore, que conociera tanto prestigio en la Italia del siglo XIII» ${ }^{14}$. Las aspiraciones joaquinistas nutrieron a los franciscanos observantes de tal manera que éstos jugaron un papel preponderante en la iglesia española, a partir del siglo XVI $1^{15}$. El hecho de que la reforma del Padre Guadalupe se implantara al mismo tiempo que la conquista de México se interpretó de manera providencial. Como señala Baudot, «la familia seráfica tendría así la inmensa suerte de poder desempeñar un papel decisivo en la ordenación final de la humanidad, tal como la Sagrada Escritura la anunciara y tal como la historia del momento la ofrecía» ${ }^{16}$. Los franciscanos se dedicaron, bajo estos presupuestos, a la predicación y a la conversión como conquista espiritual, e influenciados por la creencia de la inminente llegada del fin del mundo.

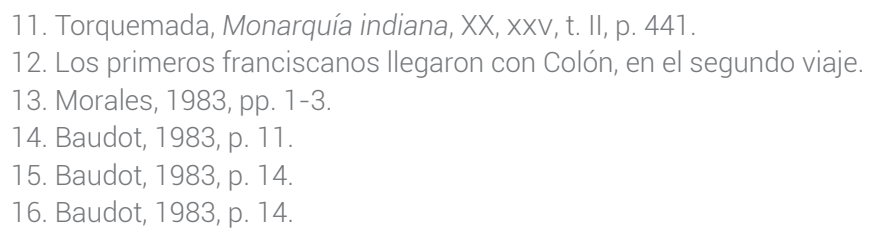


El franciscanismo de primera hora se guio por los apóstoles en su intento de volver a los tiempos primitivos, basados en la pobreza y la predicación, con una visión utópica e idealista de la cristianización del indio. Esta época fue conocida como el «Siglo de Oro» de la evangelización. Los franciscanos de segunda hora, como Jerónimo de Mendieta, añoraron ese franciscanismo puro, heroico, de los tiempos antiguos, pues ellos vivían en un periodo de decadencia y decrepitud, «Edad de Plata» y catástrofe apocalíptica, motivos parecidos a la destrucción de Jerusalén por los babilonios. Como señala Phelan ${ }^{17}$, a partir del siglo XVII existe una notoria declinación en la moral, la disciplina y la efectividad de los franciscanos de la Nueva España, en tanto en el siglo XVIII vuelven al entusiasmo evangélico con la esperanza de extender las fronteras.

Dado el papel fundamental que los propios franciscanos se asignaron en la ordenación final de la humanidad, el objetivo común de los cronistas franciscanos en el Nuevo Mundo (fray Toribio de Benavente o Motolinía, Jerónimo de Mendieta, Diego Valadés o Joaquín Bolaños, entre otros) era dar fe de la extraordinaria labor de evangelización realizada por la orden seráfica frente a determinadas políticas opuestas a su ideario y misión, sintiéndose temerosos ante su pérdida de poder.

\section{EL ORIGEN DE LOS INDIOS}

Si bien fray Toribio defendió la conquista americana, no aceptó la idea aristotélica de una sociedad jerárquica, pues el cristianismo reconoce la igualdad de todos los hombres. Aunque no se apoyó en el mito del buen salvaje, tuvo una opinión elevada de los indios al entender que ellos eran el receptáculo ideal del cristianismo. Motolinía creía que los indios eran esencialmente buenos, aunque manipulados por el demonio, y que los españoles podían dividirse entre los que se habían dejado llevar por la codicia o el odio al indio y los que habían obrado según la ley de Cristo y se habían redimido. El autor de la Historia expresa su admiración por el indio, el cual, frente al europeo, no ha deshecho el orden colectivo y a cuyo porvenir está ligado (de ahí que crea en los calendarios o presagios), esto es, que se integra rápidamente en el cristianismo y lo hace masivamente, con obediencia y humildad (millones de indios querían ser bautizados), y si bien destaca, entre sus ritos o costumbres, los horrendos sacrificios humanos, los cree culpa del demonio, salvando al indio de este modo del pecado y concediéndole el poder de la redención.

Con respecto al origen de los indios, tema de gran repercusión en toda Europa y planteado con insistencia en las crónicas de Indias, nuestro autor aventura posibles explicaciones, aunque parece decantarse por la idea de que proceden de un tronco común, el de Noé, resolviendo de esta manera el problema histórico-teológico de la naturaleza de los pobladores de esas tierras, al incorporarlos a la historia universal de la salvación cristiana. Y si bien nuestro fraile soslaya la pregunta de por qué el cristianismo no llegó a los indios, sí que parece entender que ha sido por culpa del demonio, que les ha tenido engañados. En este sentido, hay que recordar que Diego Durán, barajando diversas hipótesis, apuntaba a que podía ser que el demonio hu-

17. Phelan, 1972, p. 154. 
biera elaborado una religión falsa, haciéndose venerar como si fuese el verdadero Dios. Motolinía legitima la conquista por diversas razones: demuestra, etnográfica e históricamente, que los aztecas eran un pueblo usurpador y bárbaro y que, por lo tanto, los españoles estaban legitimados para conquistarlos. Esta idea tendrá honda repercusión en posteriores crónicas. En la esfera divina, incluso practicará una estrategia finalista, en el sentido de que interpretará la realidad a partir de los textos bíblicos y, como Colón en El libro de las profecías, relacionará determinados pasajes bíblicos con la misión evangélica. La conquista, de este modo, se habría realizado por permisión divina.

En el ámbito sociocultural, la idolatría y sobre todo los sacrificios humanos así como las ideas seráficas sobre el milenarismo otorgan a la conquista militar y espiritual visos de urgencia. Frente a esta idea, Las Casas incluso llegará a comprender los sacrificios humanos como estrategia argumental para defender la ilegitimidad de la conquista. Son muchas las ocasiones en que Motolinía no solo apoya la labor realizada por Cortés, sino que expresa su admiración por el conquistador que supo, gracias a su flexibilidad mental, sus escaramuzas y estrategias, dominar a los indios. Se enfrenta por lo tanto a Las Casas, quien abogaba por una conquista llevada a cabo solo por religiosos y no por soldados, sintonizando de este modo con una sociedad teocrática medieval. Muy posiblemente por ello, nuestro autor, en franca oposición con el dominico, pide en su Historia que se levanten fortalezas para proteger a los españoles o defiende con contundencia las acciones de Cortés. Fray Toribio, como entiende que la conquista es legítima, no cree que deba restituirse a los indios, ni que éstos deban conservar el señorío de sus territorios o que puedan decidir ellos mismos sobre su porvenir. Carlos V, siguiendo la política colonial, es el monarca de todos. Una vez más, las posturas de las órdenes en materia de política colonial estaban bien alejadas.

\section{LA RECONQUISTA DE JERUSALÉN Y EL FIN DE LOS TIEMPOS}

Para los cristianos el fin del mundo era algo inminente al considerar que Jesús era el Mesías enviado por Dios para establecer su reino: En Lucas se afirma que Jesús «se encontraba cerca de Jerusalén y ellos pensaban que el reino de Dios estaba a punto de manifestarse» ${ }^{18}$. Pero Cristo no toma el poder, se deja arrestar y crucificar. Cristo había anunciado el fin próximo de Jerusalén (tendrá lugar en el año 70 d. C. bajo Tito), pero para sus discípulos una catástrofe de ese tipo solo era concebible al final de la Historia. Por eso le preguntan: «Dinos, ¿cuándo sucederá y cuál será el signo de tu llegada y del fin del mundo»?

La reconquista es percibida, al menos por algunos, como un preludio de los últimos tiempos. El establecimiento, en Jerusalén, de un poder cristiano en lugar del poder musulmán establecido por la fuerza varios siglos antes es un objetivo político, pero también religioso: el Anticristo, que pronto va a aparecer, debe enfrentarse a un poder cristiano en Jerusalén. Es necesario, antes, que Jerusalén vuelva a ser cristiana. El tema aparecerá, como a continuación veremos, representado en

18. Lucas, 19, p. 11 
los autos de las fiestas celebradas en Tlaxcala, en los tiempos en que Motolinía moraba en dicha ciudad.

No ha llegado hasta nosotros ni un solo fragmento de dichos Autos o comedias en lengua mexicana, supuestamente escritos por Motolinía ${ }^{19}$, si bien es cierto que en la Historia se describe el argumento, la escenificación y la tramoya de varios autos celebrados en Tlaxcala entre 1538 y 1539. Aunque ninguna de las fuentes primitivas le atribuya a Motolinía la autoría de ningún tipo de obra teatral, parece que no hay duda de que algunos de estos primeros doce frailes que llegaron a México compusieron autos o misterios con un objetivo evangelizador.

Gómez Canedo señala, al respecto, que el teatro religioso novohispano, del que los franciscanos fueron «los principales, o casi únicos, en valerse» ${ }^{20}$, no solo continuaba con una larga tradición española de teatro religioso sino que, además, entroncaba con las prácticas prehispánicas de los indios mexicanos. En el caso de Motolinía, al ser él quien dirigía toda la actividad misionera durante los años que ejerció de guardián en Tlaxcala, no parece inoportuno conjeturar que muchos de los autos representados el día del Corpus, en la fiesta de San Juan y por Pascua, en 1538, salieran de su pluma, máxime cuando en su Historia, además de dar detalles de ellos, recalca la rapidez con que se habían escrito:

Porque se vea la habilidad de estas gentes diré aquí lo que hicieron y representaron luego adelante el día de San Juan Babtista, que fue el lunes siguiente. Y fueron cuatro autos que sólo para sacarlos dichos en prosa, que no es menos devota la historia que en metro, fue bien menester todo el viernes, y en solos dos días que quedaban, que fueron sábado y domingo, lo deprendieron, y representaron harto devotamente la Anunciación de la Natividad de San Juan Bautista hecha a su padre Zacarías, que se tardó en ella obra de una hora, acabando con un gentil motete en canto de órgano. Y luego adelante en otro tablado representaron la Anunciación de Nuestra Señora, que fue mucho de ver, que se tardó tanto como el primero. Después en el patio de la iglesia de San Juan, ado fue la procesión, luego en allegando antes de misa, en otro cadalso representaron la Visitación de Nuestra Señora a Santa Elisabet. «Después de misa se representó la Natividad de San Juan y en lugar de la circuncisión, fue batismo de un niño de ocho días nacido que se llamó Juan, y antes que diesen al mudo Zacarías las escribanías que pedía por señas, fue bien de reír lo que le daban, haciendo que no le entendían ${ }^{21}$.

Entiende Lejarza que los autos de la Anunciación, del nacimiento del Bautista, de la Anunciación a la Virgen, de la Visitación y del nacimiento del Precursor se

19. Nuestro interés en el presente artículo no es el estudio de los autos o representaciones teatrales sino los temas de la conquista de Jerusalén y el milenarismo que aparecen en los mismos. Para un estudio detallado de los autos, véase: Sacrificio de Isaac. Auto en lengua mexicana, escrito en el año 1678, Florencia, Tipografía de Salvador Landi, 1899; El sacrificio de Isaac. Obra de teatro tlaxcalteca del siglo XVI, publicada en 1899 por Francisco del Paso y Troncoso, compiladora Guadalupe Alemán Ramírez, México, Impretei, 2013; y, por supuesto los estudios clásicos de Horcasitas, León-Portilla, Sten y Viveros, 2004, Arróniz, 1979, Garibay, 1987, Duverger, 1987, y Gómez Canedo, 1988.

20. Gómez Canedo, 1988, p. 115.

21. Motolinía, Historia de los indios de la Nueva España, p. 164. 
escribieron en Tlaxcala el viernes, 21 de junio de 1538, a toda prisa, «porque la idea y resolución de representarlos había surgido de momento y bajo el entusiasmo suscitado por las fiestas del Corpus, que había sido el día anterior», y que varios misioneros se pondrían manos a la obra, siendo «Motolinia el que llevó el mayor peso» ${ }^{22}$. Sin embargo, Gómez Canedo comenta que las descripciones que hace nuestro cronista, en el capítulo 15 de la «Primera parte» de la Historia, «no siempre aclaran del todo el carácter de tales representaciones»; y recalca que «la del Corpus de 1538 puede no haber sido más que una espectacular procesión, solemnizada con cuadros plásticos de maravilloso artificio, pero en la que no se encuentra ni libreto, ni diálogos ni actores» ${ }^{23}$, si bien es cierto que «fray Bartolomé de las Casas, que utilizó otra versión del propio Motolinía para insertar su relato en la Apologética, la califica de auto».

El capítulo decimocuarto de la Historia, de Motolinía, finaliza con dos cartas interpoladas escritas por «un fraile morador de Tlaxcala» y dirigidas al provincial de la orden franciscana, fray Antonio de Ciudad Rodrigo, en las que se describen las representaciones de los mentados cuatro autos. La primera trata de «la penitencia y restituciones que hicieron los tlaxcaltecas en la cuaresma pasada del año de 1539, y cómo celebraron la fiesta de la Resurrección y Anunciación». En la misma se detalla, asimismo, cómo pintaron los indios la capilla, que hoy ya no existe y sobre la que se construyó el convento franciscano de Nuestra Señora de la Asunción de Tlaxcala, y los divinos oficios con cantos y músicas:

Tenían cerca de la puerta del hospital aparejado para representar un auto, que fue la caída de nuestros primeros padres, y al parecer de todos los que lo vieron fue una de las cosas notables que se han hecho en la Nueva España. Estaba tan adornada la morada de Adán y Eva, que bien parecía paraíso de la tierra, con diversos árboles con frutas y flores, de ellas naturales y de ellas contrahechas de pluma y oro ${ }^{24}$.

La segunda epístola describe «las fiestas que se hicieron en Tlaxcala por las paces hechas entre el Emperador y el rey de Francia». Se trata del auto que representa «La conquista de Jerusalén». Aparte de los acalorados debates acerca de la autoría de ambas cartas y de que se trata de uno de los testimonios más importantes del teatro evangelizador del siglo XVI, dicho capítulo es fundamental porque los autos descritos suponen una exaltación del papel de la Orden Seráfica en la conversión de los indios de la Nueva España. Asimismo, la representación de dichos autos puede ser vista como una exhibición de fuerza por parte de los franciscanos frente a la iglesia secular, la cual, en la época en la que Motolinía escribió su Historia, les disputaba el protagonismo en la Nueva España. Por si esto no fuese suficiente, varios de los autos descritos, especialmente el que trata el tema de la conquista de Jerusalén, presentan elementos interesantes para la polémica acerca del carácter milenarista de dicha obra. 
En el auto de la conquista de Jerusalén, al final de la obra, la ficción teatral y la realidad histórica coinciden: un sacerdote verdadero bautiza a los indios disfrazados de moros.

Según Arróniz, frente al bastión de la idolatría (Jerusalén) combaten los españoles (franciscanos, dominicos, agustinos...) pero no es suficiente (son contenidos por los representantes de la idolatría: los moros), siendo necesaria la intervención de los propios indios (en la obra se les dice expresamente «el ejército de nahuales»). Aun cuando la idolatría puede parecer victoriosa, Dios enviará a San Hipólito (patrón de los indios; recuérdese que en el día de San Hipólito se conmemoraba la caída de Tenochtitlán en manos españolas) como envió en su tiempo a Santiago, para hacerlos vencer en la lucha ${ }^{25}$. Según la hipótesis de Arróniz, La conquista de Jerusalén sería «una demostración de fuerza de la orden franciscana, frente a grupos de la propia Iglesia que veían con descontento la hegemonía política gozada por ella desde los años siguientes a la Conquista» ${ }^{26}$. Más concretamente, se trataría de una defensa de la práctica franciscana del bautizo por aspersión, práctica muy recientemente censurada por el Papa Paulo III.

Hay que recordar aquí que Motolinía discute la polémica sobre el bautismo en el capítulo cuarto de la «Segunda parte» de su Historia, en donde resumirá las diferentes posiciones que existían sobre la administración del bautismo en la iglesia novohispana y se pronunciará contra la determinación de los obispos mexicanos que, en el sínodo eclesiástico celebrado el mes de abril de 1539, habían ordenado la aplicación en México de la bula Altitudo divini consilii del Papa Pablo III, del 1 de junio de 1537, en la que se prohibían los bautizos masivos que practicaban los franciscanos. La importancia del bautismo en el plan milenarista es máxima pues la conversión de cuantos indios fuese posible era un modo de acelerar dicho proyecto milenario ${ }^{27}$.

Varios de los autos descritos en el capítulo 15 de la «Primera parte» de la Historia contienen, además, diversas referencias milenaristas. Es incuestionable el caso del auto del Juicio Final ${ }^{28}$, que, según Frost, es «uno de los pocos testimonios sobrevivientes de la problemática milenarista y apocalíptica de los franciscanos» ${ }^{29}$. Si tenemos en cuenta con Horcasitas, León-Portilla, Sten y Viveros ${ }^{30}$ que el tema del Juicio Universal no tenía antecedentes directos en el teatro castellano anterior a la conquista, coincidiremos con Surtz en que los misioneros franciscanos «idearon un auto de acuerdo con sus ideas apocalípticas y su visión del papel de los indios

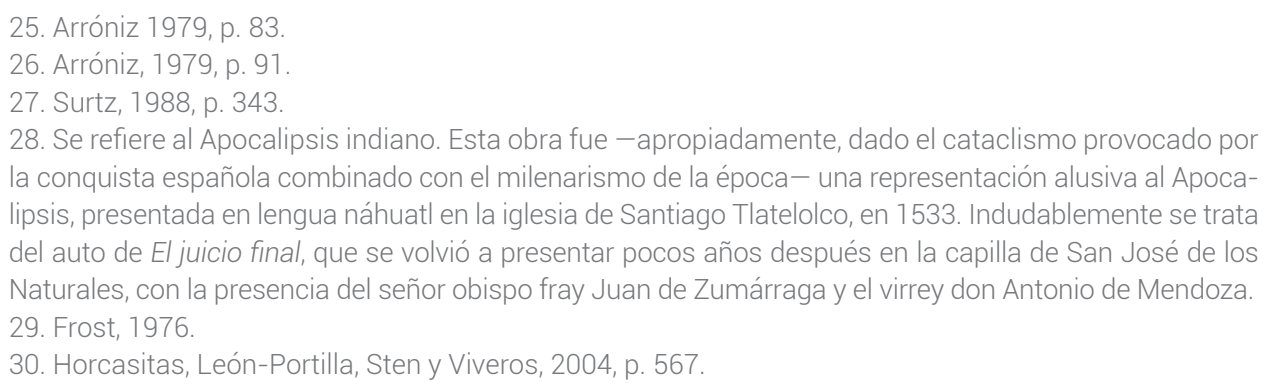


en el cumplimiento del milenio» ${ }^{31}$. También el auto que trata el tema de la conquista de Jerusalén, cuya recuperación por parte de un emperador cristiano era un requisito fundamental para que el desenlace cósmico tuviese lugar, contiene referencias milenaristas ${ }^{32}$.

Incluso en el auto sobre la Epifanía podrían verse resonancias milenaristas, puesto que los indios no son presentados como pastores, esto es, como judíos, que según el imaginario cristiano medieval sería un pueblo irreductible, sino como gentiles, de modo que el papel reservado a los indios en la historia de la salvación sería salvarse a última hora ante la proximidad de la parusía, tal y como sugería la primera epístola de San Pedro.

El milenarismo ha sobrevivido a lo largo de la historia cristiana con sus brotes y rebrotes. América fue un terreno fértil en donde sembrar la creencia de una tierra prometida más allá del Atlántico. Los franciscanos de segunda hora, como Jerónimo de Mendieta, añoraron ese franciscanismo puro, heroico, de los tiempos antiguos. El milenarismo pervivió a lo largo del siglo XVIII como bien se observa, por ejemplo, en la protonovela o sermón del franciscano Joaquín Bolaños, La portentosa vida de la muerte. Dicha obra puede ser considerada como un relato de los signos anunciadores y preparatorios del fin de los tiempos. Bolaños habría heredado dicha doctrina a través del espiritualismo franciscano que, tras haber sobrevivido de forma minoritaria y encubierta, habría renacido en España durante los siglos XV y XVI, gracias, en parte, a la figura del cardenal Jiménez de Cisneros, observante franciscano.

En el siglo XX, las ideas milenaristas pueden rastrearse en las exégesis del jesuita chileno Manuel Lacunza, así como en otros grupos o proyectos políticos de salvación universal. En Europa su difusión llegó a los ilustrados alemanes y franceses (el milenarismo lleva en sí la idea de la concepción de la historia como progreso), a los seguidores de Hegel, a positivistas como Comte y al pensamiento comunista y socialista, además de a los protestantes. El historiador británico Eric Hobsbawm analiza tres tipos de milenarismo de los siglos XIX y XX: los lazaretistas de Toscana meridional, los anarquistas aldeanos de Andalucía y los movimientos campesinos sicilianos, y señala que el milenarismo es un «fenómeno utilísimo que los movimientos sociales y políticos modernos pueden utilizar con provecho para difundir el ámbito de su influencia y para dejar la impronta de su doctrina en los grupos de hombres y mujeres por él afectados» ${ }^{33}$. Según las profecías de San Malaquías, tras el Papa Francisco vendrá otro Papa y seguidamente llegará el fin del mundo. Ideologías utópicas o síndrome del milenarismo clásico que se extenderá a ciertos movimientos revolucionarios del siglo Xx y que, como advierte Gray, envenenarán la vida de mucha gente ${ }^{34}$.

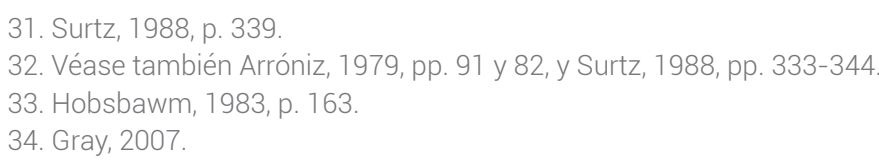




\section{BiBLIOGRAFÍA}

Alemán, C. Guadalupe, «Introducción», en Sacrificio de Isaac. Obra de teatro tlaxcalteca del siglo XVI en náhuatl y castellano, publicada en 1899 por Francisco del Paso y Troncoso, México D. F., Impretei, 2013.

Arróniz, Othón, Teatro de evangelización en Nueva España, México D. F., UNAM, 1979.

Baudot, Georges, Utopía e historia en México, Madrid, Espasa-Calpe, 1983.

Duverger, Christian, La conversion des indiens de Nouvelle Espagne, avec le texte des Colloques des Douze de Bernardino de Sahagún, Paris, Éditions du Sevil, 1987.

Frost, Elsa Cecilia, «El milenarismo franciscano en México y el profeta Daniel», Historia Mexicana, XXVI, 1, 1976, pp. 3-28.

Garibay, Ángel María, Historia de la literatura náhuatl. I: Etapa autónoma; II: El trauma de la conquista (1521-7750), México D. F., Porrúa, 1987.

Gray, John, Misa negra. La religión apocalíptica y la muerte de la utopía, Barcelona, Paidós, 2007.

Gómez Canedo, Lino, Pioneros de la cruz en México: Fray Toribio de Motolinía y sus compañeros, Madrid, Biblioteca de Autores Cristianos, 1988.

Hobsbawm, Eric, Rebeldes primitivos. Estudio sobre las formas arcaicas de los movimientos sociales en los siglos XIX y XX, Barcelona, Ariel, 1983.

Horcasitas, Fernando, León-Portilla, Miguel, Sten, María, y Viveros, Germán, El teatro náhuatl: épocas novohispana y moderna, México D. F., UNAM, 2004.

Lejarza, Fidel de, «Estudio preliminar», en Toribio Benavente de Motolinía, Memoriales e Historia de los indios de la Nueva España, Madrid, Atlas, 1970 (BAE, 260-261), pp. V-XXI.

Morales, Francisco, «Los franciscanos en la Nueva España. Laépoca de oro, siglo XVI», en Franciscan Presence in the Americas. Essays on the Activities of the Franciscan Friars in the Americas, 1492-1900, ed. Francisco Morales, Washington, Academy of American Franciscan History, 1983.

Motolinía, fray Toribio Benavente, Historia de los indios de la Nueva España, ed., introducción y notas Mercedes Serna y Bernat Castany, Madrid, Real Academia Española, 2014.

Motolinía, fray Toribio Benavente, Memoriales e Historia de los indios de la Nueva España, ed. Fidel de Lejarza, Madrid, Atlas, 1970 (BAE, 260-261).

O'Gorman, Edmundo, El libro perdido de Fray Toribio Motolinía. Ensayo de reconstrucción de la obra histórica extraviada de Fray Toribio Motolinía, México D. F., Consejo Nacional para la Cultura y las Artes, 1989. 
Phelan, John L., El reino milenario de los franciscanos en el Nuevo Mundo, México D. F., UNAM, Instituto de Investigaciones Históricas, 1972.

Surtz, Ronald E., «Pastores judíos y reyes magos gentiles: teatro franciscano y milenarismo en Nueva España», Nueva Revista de Filología Hispánica, XXXVI, 1, 1988, pp. 333-344.

Torquemada, Juan de, Monarquía indiana, ed. Miguel León-Portilla, México D. F., Porrúa, 1986, 3 vols. 